\title{
CORRIGENDUM
}

\section{Soil metal/metalloid concentrations in the Clyde Basin, Scotland, UK: implications for land quality - CORRIGENDUM}

\author{
F. M. FORDYCE, P. A. EVERETT, J. M. BEARCOCK and T. R. LISTER
}

http://dx.doi.org/10.1017/S1755691018000282. Published online by Cambridge University Press

21 November 2018

KEY WORDS: arsenic, cadmium, chromium, land contamination, lead, nickel, selenium, topsoil, CORRIGENDUM.

In the above article (Fordyce, F., Everett, P., Bearcock, J., \& Lister, T. (2019)), Figure 7 was not published in its entirety. The correct figure should be as follows:
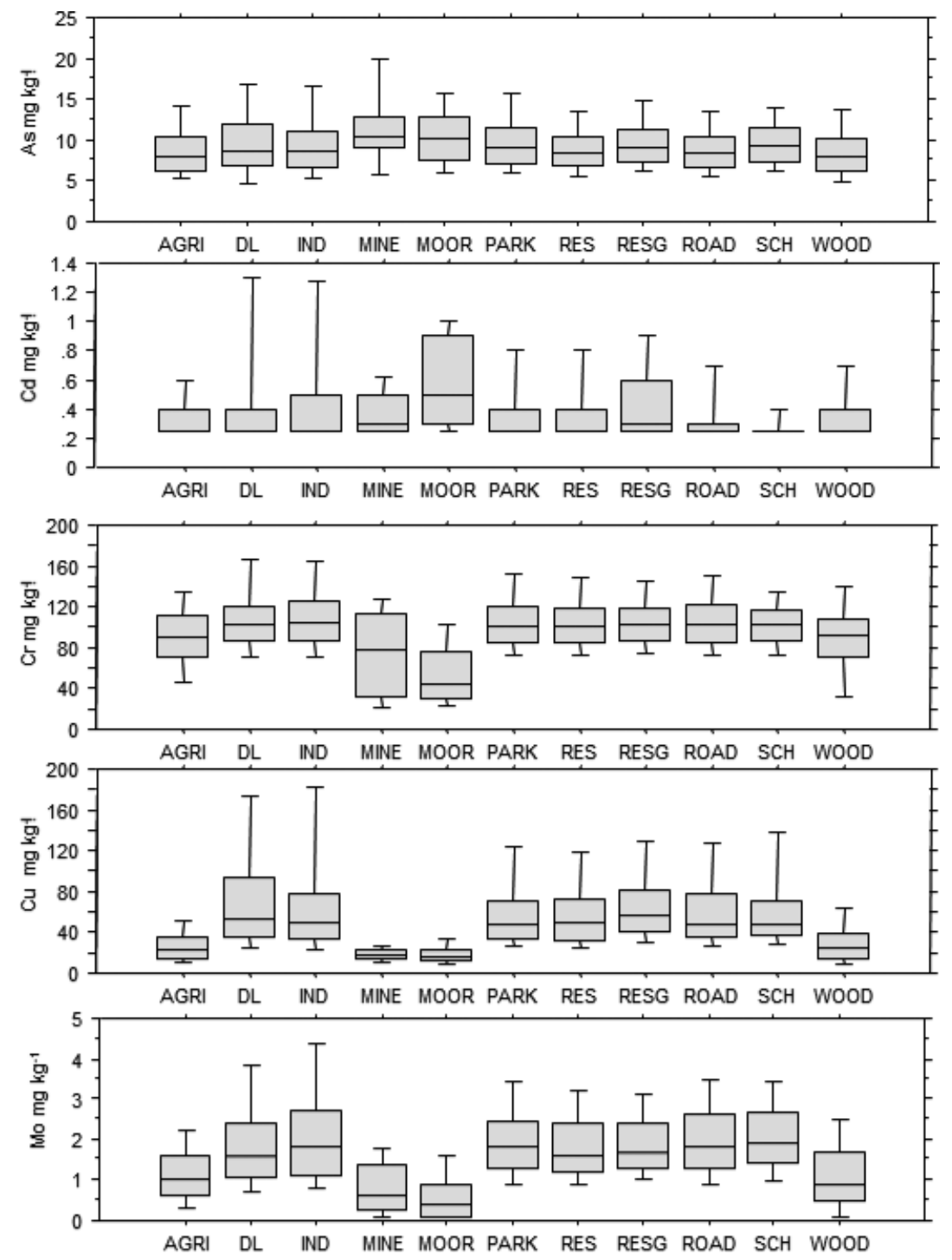

Figure 7 Box and whisker plots showing the 10 th, $25^{\text {th }}, 50^{\text {th }}, 75$ th and 90 th percentiles of parameter distributions in topsoil over various land-use types. Abbreviations: AGRI = agriculture (n1303); DL $=$ derelict land (n124); IND = industry (n236); MIN = mining (n33); MOOR = moorland (n151); PARK = recreational (n656); RES = residential open space (n347); RESG = garden/allotment (n254); ROAD = road/rail (n579); $\mathrm{SCH}=$ school $(\mathrm{n} 72) ;$ WOOD $=$ woodland $(\mathrm{n} 189)$. 

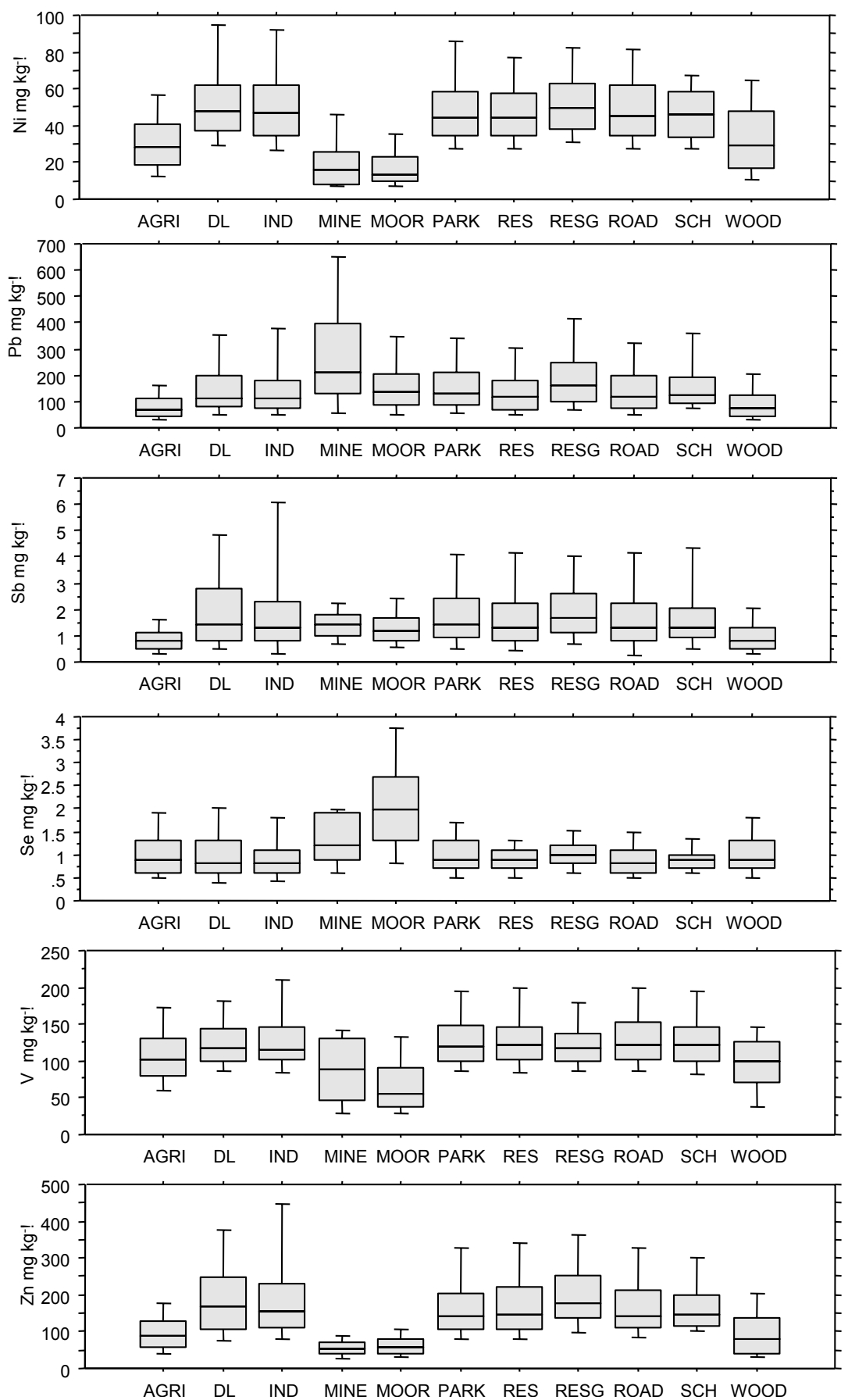

Figure 7 Continued

\section{Reference}

Fordyce, F., Everett, P., Bearcock, J., \& Lister, T. (2019). Soil metal/ metalloid concentrations in the Clyde Basin, Scotland, UK: Implications for land quality. Earth and Environmental Science

Transactions of the Royal Society of Edinburgh, 108(2-3), 191-

216. doi:10.1017/S1755691018000282 